\title{
Histological and Immunohistochemical study on the Changes Induced by Contraceptive pills in the female rabbit's kidney
}

\author{
Abdel Kader DH*, Gabri MS**, Ibrahim MA**, Hassan BN** \\ *Department of histology, Faculty of Medicine, Cairo University. \\ **Department of zoology and entomology, Faculty of Science, Helwan University.
}

\begin{abstract}
Background: The mechanism for the development of overt hypertension due to the oral contraception ingestion remains unclear. Experimental evidence favors a role for the renin-angiotensin system. The present study focuses on evaluating the effect of two different contraceptive pills including combined pills (estrogen and progesterone) and mini pills (progesterone only) on the kidney of female rabbit.

Material and methods: After three month of daily oral administration of these contraceptive pills the animals were sacrificed. The excised kidneys were dissected, processed and stained with H \& E, PAS and Masson's trichrome and anti-angiotensin II immunohistochemical stains. This was followed by morphometric measurements and statistical study.

Results: This study revealed that contraceptive pills administration specially the combined one caused marked alterations in the form of damaged kidney tubules with cell swelling and loss of brush border and enlarged glomeruli with hypercellularity. Also, a statistically significant increase in collagenous content peritubular and peri and intraglomerular was observed. There was also a statistically significant increase in the anti-Angiotensin II immunoreactivity in renal tubules as well as intra-glomerular and in the interstitial cells. All these changes were less marked after mini pill treatment.
\end{abstract}

Conclusion: Progesterone only pills could be safer on the kidney as a contraceptive mean when compared to combined pills.

Key words: combined pills -mini pills- rennin-angiotensin system - angiotensinII- kidneyimmunohistochemistry

\section{Introduction}

The idea of using hormones for contraception was first suggested in the 1920s when the ovarian hormones, oestrogen and progesterone, and their role in reproduction were discovered (David et al., 2009)

By the end of the 1960s, a link between high levels of oestrogen in the pill and the risk of users developing blood vascular problems as blood clots and strokes was being studied (Carol, 2005)

The mechanisms responsible for the hypertensive effect of oral contraceptives are poorly understood. The renin-angiotensin system may be involved, since estrogen stimulates the hepatic production of the renin substrate, angiotensinogen (Darrell and Melissa, 2008).

Over the last few decades, the understanding of the renin-angiotensin system (RAS) has advanced dramatically. The RAS is now thought to play a crucial role in physiologic and pathophysiologic mechanisms in almost every organ system and is a key regulator of hypertension and renal function (Abadir, 2011). Angiotensin II (AngII) is the most powerful 
biologically active product of the RAS, it directly constricts vascular smooth muscle cells, enhances myocardial contractility, stimulates aldosterone production, stimulates release of catecholamines from the adrenal medulla and sympathetic nerve endings, increases sympathetic nervous system activity, and stimulates thirst and salt appetite. It regulates sodium transport by epithelial cells in intestine and kidney (Kobori et al., 2007).

A fall in blood pressure causes local and sympathetic nerve driven secretion of renin, from a group of cells located in the juxtaglomerular apparatus (JGA) of the kidney, a structure formed by the physically close association of cells of the distal convoluted tubule and the afferent blood capillary. Renin diffuses into blood stream catalyzing the conversion of angiotensinogen into angiotensin I. In the lungs, the latter is then transformed into angiotensin II via angiotensin-converting enzyme (ACE) (William and Stephen, 2007)

Angiotensin-II induces stimulation of tubular cells and causes an increase in plasma osmolality by the action of aldosterone. The rise in osmolality stimulates the release of $\mathrm{ADH}$ (vasopressin) from the pituitary resulting in enhanced water reabsorption from the distal portions of the nephron and thus increases the blood volume and pressure (Reed, 2009)

Recent researches have shown that RAS occur in certain other tissues such as the pancreas, adipose tissue, brain and ovary, presumably to regulate local blood dynamics (Leung and Chappell, 2003)

\section{Aim of the study:}

The present study aimed at eliciting the changes that can be induced by contraceptive pills in the kidney and intra-renal angiotensin by means of histological and immunohistochemical methods.

\section{Material and methods}

\section{Material:}

\section{1- The drugs:}

The drugs used in this work were mini contraceptive pills (progesterone only) for group of animals, and combined pills (progesterone and estrogen) for another group as a daily dose for three months. They were purchased in tablets form that were crushed to powder and dissolved in distilled water and their doses were calculated according to the interspecies dosage conversion scheme of Goush (Paget and Barnes, 1964). The mini pills tablets contained $0.5 \mathrm{mg}$ lynestrenol (Organon Oss Holland, Holland). Combined pills tablet contained $0.105 \mathrm{mg}$ combined hormones (Kahira Pharm, Cairo, Egypt). Drugs were given orally using special blunt-tipped needle fixed on an ordinary syringe.

\section{2- The animals:}

Fourteen adult female rabbits with an average body weight of about $1.5 \mathrm{~kg}$ were obtained from the farm of the Egyptian Organization of Biological Products and Vaccines in Helwan, Cairo. They were kept under good hygienic conditions and fed ad libitum and allowed free water supply.

The animals were divided into the following groups:

\section{A- Control group:}

Consisted of two animals that did not receive any drug or vehicle.

\section{B- Mini pills group:}

Consisted of six animals that received a daily dose of $0.0035 \mathrm{mg} /$ day in $0.2 \mathrm{ml}$ distilled water. This dose is equivalent to the daily therapeutic dose of human $0.5 \mathrm{mg} /$ day.

\section{C- Combined pills group:}

Consisted of six animals that received a daily dose of $0.00735 \mathrm{mg} /$ day in $0.2 \mathrm{ml}$ distilled water and was equivalent to therapeutic dose of human $0.105 \mathrm{mg} /$ day

\section{Methods:}

Twenty four hours after the last dose all animals were sacrificed and the dissected left kidneys were subjected to the following:

\section{1- For histological and histochemical examination:}

The excised organ was fixed in Carnoy solution for about four hours, dehydrated, cleared in xylene and impregnated in paraplast for blocks 
formation, serial sections of 5 um thickness were prepared and stained with: Hematoxylin and Eosin, Periodic acid Schiff's and Masson's trichrome (Bancroft and Gamble,2002).

\section{2- For immunohistochemical examination:}

Five-micron sections of kidneys fixed with Bouin's fixative were immunostained using antiangiotensin II primary antibody (Labvision, Neomarkers, USA) for 90 minutes. This was followed by the secondary antibody application using the immunoperoxidase technique (Vectastain ABC kit; Vector Laboratories, Burlingame, CA). Sections were counterstained with hematoxylin (Bancroft and Gamble, 2002). The reaction was cytoplasmic.

\section{3- Morphometric measurements:}

The measurements included the corpuscular diameter in H\&E stained sections, the optical density of periodic acid Schiff reaction, the area percent of collagen in Massons trichrome stained slides. Also, the mean area percent as well as the optical density of the positively immunostained cells were measured. This was done using the "Leica Qwin 500C" image analyzer computer system (Leica Imaging System Ltd., Cambridge, England). All measurements were done within 10 nonoverlapping fields/section for each animal, at X400 magnification, in a standard frame of $7099.95 \mu \mathrm{m} 2$.

\section{4- Statistical analysis:}

The morphometric results were expressed as mean \pm standard deviation (SD). Statistical analysis was carried out using the "SPSS 9.0 for Windows" statistical software. Comparison between different groups was done using oneway analysis of variance (ANOVA) followed by post hoc "tuckey" test. The results were considered statistically significant when "P" value was < 0.05 (Petrie and Sabin, 2005).

\section{Results}

\section{A- Histological Results:}

\section{I- Control Group:}

The histological architecture of the cortex of rabbit kidney in $\mathrm{H}$ and $\mathrm{E}$ stained sections showed that renal corpuscles consisted of simple squamous epithelium of parietal layer of Bowman's capsule, separated by Bowman's space from the lobulated glomerular tuft of capillaries, which is covered by visceral layer of Bowman's capsule. Proximal convoluted tubules (PCT) were lined with darkly acidophilic high cuboidal epithelium with rounded nuclei and a brush border. The distal convoluted tubules (D.C.T) were lined with faint acidophilic cubical epithelial cells with rounded nuclei, and their lumen apparently wider than P.C.Ts (Fig.1).

Both capsular and glomerular basement membranes showed a PAS positive reaction. The cells of proximal convoluted tubules showed PAS positive luminal brush border. Also, thin PAS positive tubular membranes were seen investing the tubules (Fig.2).

Masson's trichrome stain revealed that the stroma of the kidney was formed of a thin fibroconnective tissue capsule and scanty interstitial connective tissue that was concentrated mainly around blood vessels. Scanty collagen content was seen surrounding the glomeruli (Fig.3)

Positive anti-angiotensin II (Ang II) immunostaining was detected mainly in the cells of distal tubules. Mild immunoreaction was also noted in few proximal tubular cells, in some glomerular cells and in some interstitial cells (Fig.4).

\section{2- Mini pills Group}

Kidney stained with $\mathrm{H}$ and $\mathrm{E}$ revealed that Bowman's space was sometimes relatively narrowed with mildly increased corpuscular diameter. Some tubules showed swollen epithelial lining cells that sometimes obliterated their lumen (Fig.5).

In the PAS stained sections there was a moderately positive reaction in the focally thickened capsular and tubular basement membranes. There was also a faint PAS reaction in the brush border of cells of PCT (Fig.6).

Moderate increase in the collagenous content was seen with Masson's trichrome stain both in glomerular and peritubular areas (Fig.7).

There was a moderately positive anti-AngII immunoreactivity in the cells of D.C.T. On the other hand, there was a mild positive reaction intra-glomerular, in the P.C.T. cells and in the interstitial cells (Fig.8). 



\section{3- Combined pills Group}

In the $\mathrm{H} \& \mathrm{E}$ stained sections marked changes were seen in the form of obliterated Bowman's space, increased diameter of corpuscles, increased intra-glomerular cellularity and tubular cell swelling leading to marked obliteration of renal tubules lumen (Fig.9).

Moderate PAS reaction was seen in the brush border of proximal convoluted tubules, in addition to marked thickening in capsular and tubular basement membranes (Fig.10).

Marked increase in the collagenous content was noticed intra-glomerular and around the renal corpuscles and the tubules (Fig.11).

Intense AngII immunostaining was observed in the cells lining both proximal and distal convoluted tubules, as well as in the interstitial cells, while, intra-glomerular there was a faint reaction (Fig.12).

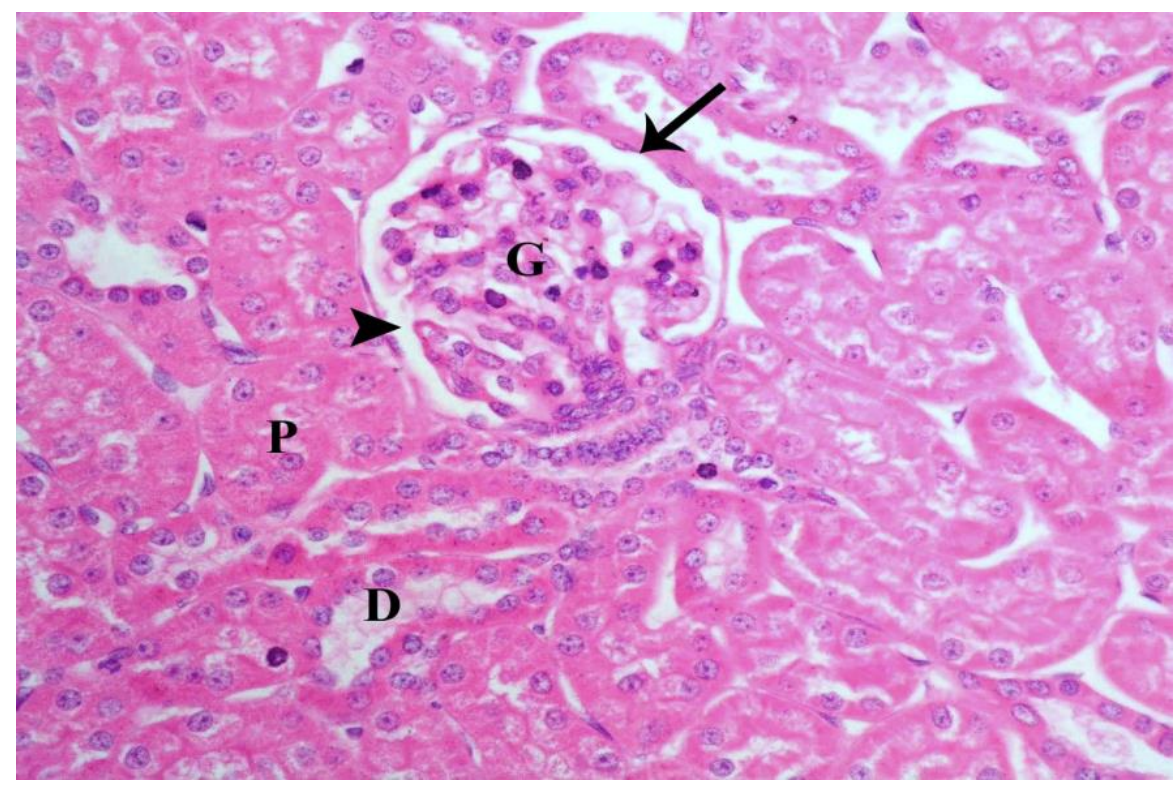

Fig.1: A photomicrograph of a section of control rabbit kidney cortex showing a malpighian corpuscle where the parietal layer of Bowman's capsule (arrow) is lined with simple squamous epithelium and the glomerulus $(\mathrm{G})$ is formed of lobulated tuft of capillaries being separated from the capsule by Bowman's space (arrowhead). Normal proximal (P) and distal tubules (D) are also seen.

H\&E X400 


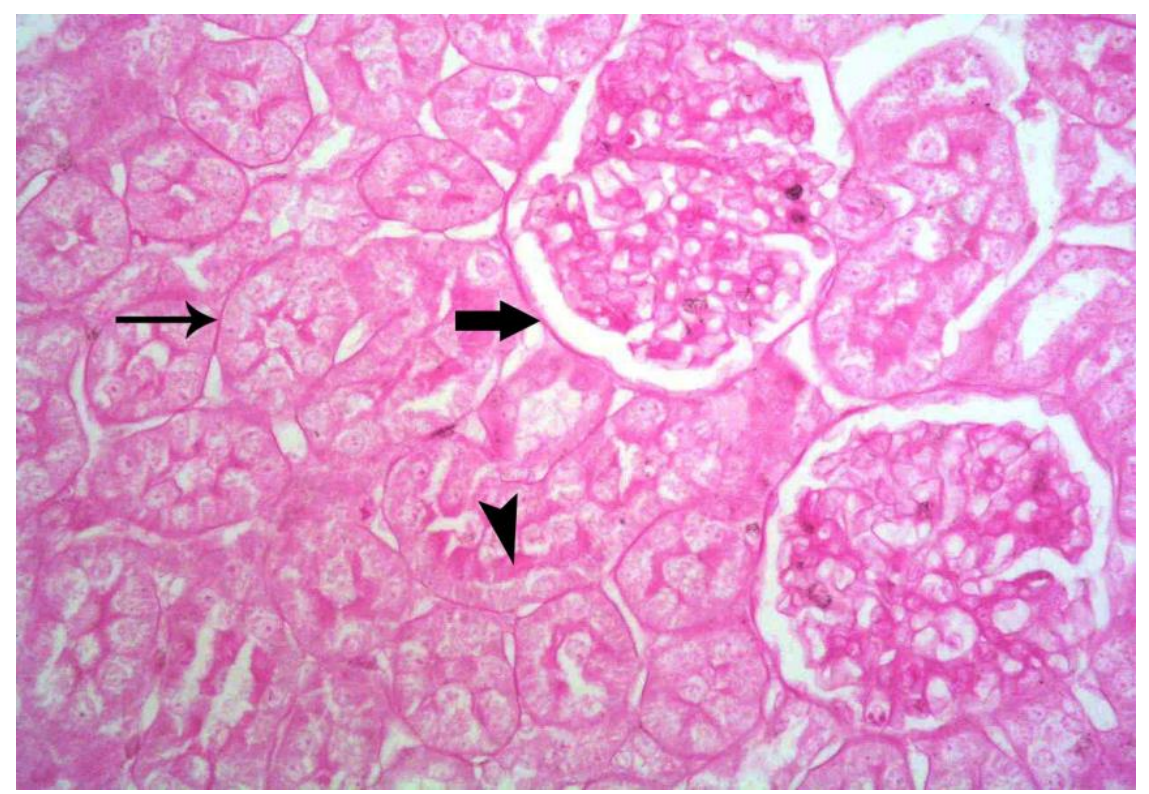

Fig.2: A photomicrograph of a section of control rabbit kidney cortex showing positive PAS reaction in capsular (thick arrow) and tubular (thin arrow) basement membranes and in the apical brush borders of PCT cells (arrowhead).

PAS reaction $x 400$

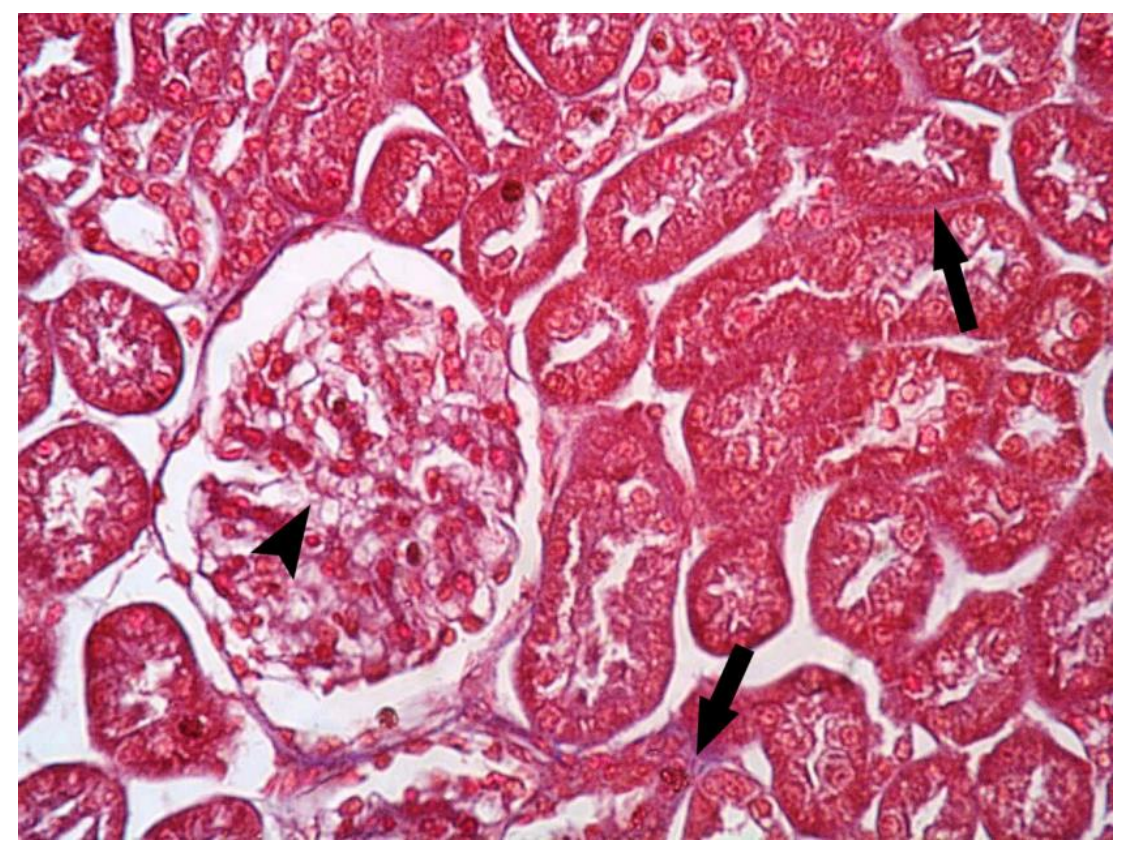

Fig.3: A photomicrograph of a section of control rabbit kidney cortex showing a scanty interstitial C.T. around tubules (arrow) and inbetween the glomerular tuft of capillary (arrowhead). 
Histological and......

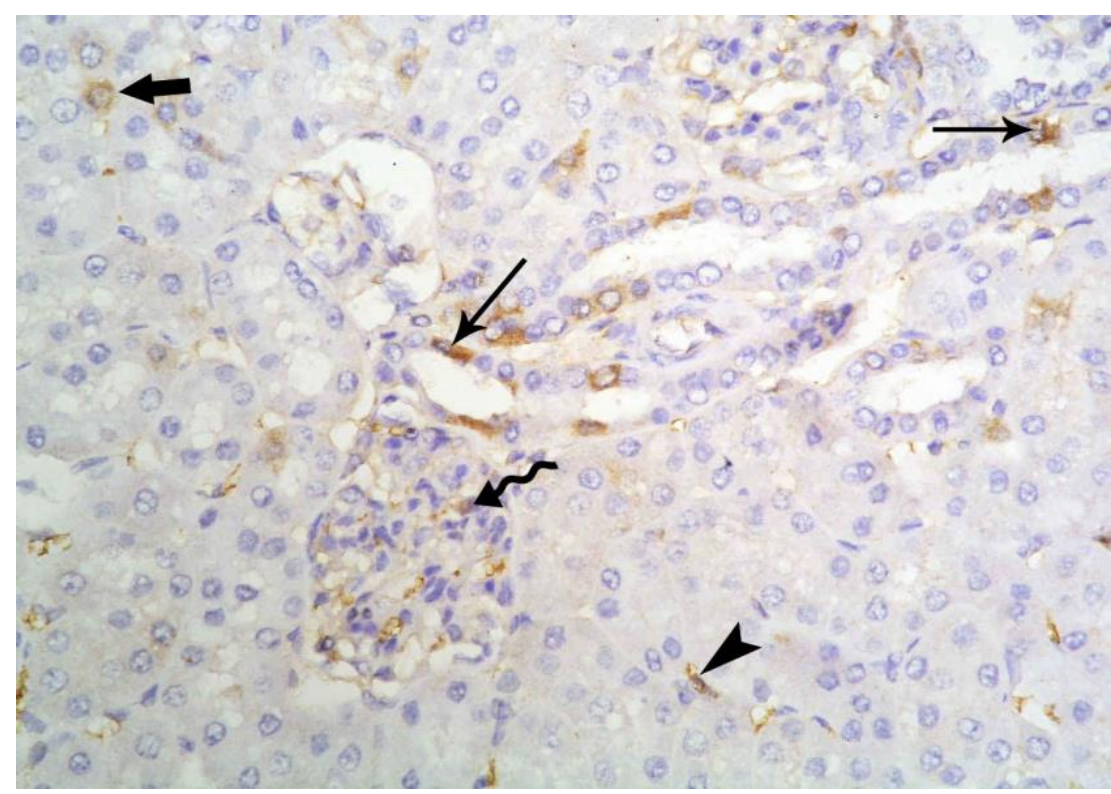

Fig.4: A photomicrograph of section of control rabbit kidney cortex showing positive immunoreactivity for angiotensin II in the cytoplasm of some D.C.T. (thin arrow), few P.C.T.(thick arrow), interstitial cells (arrowhead) and intraglomerular (wavy arrow).

Anti- angiotensin II immunostaining x400

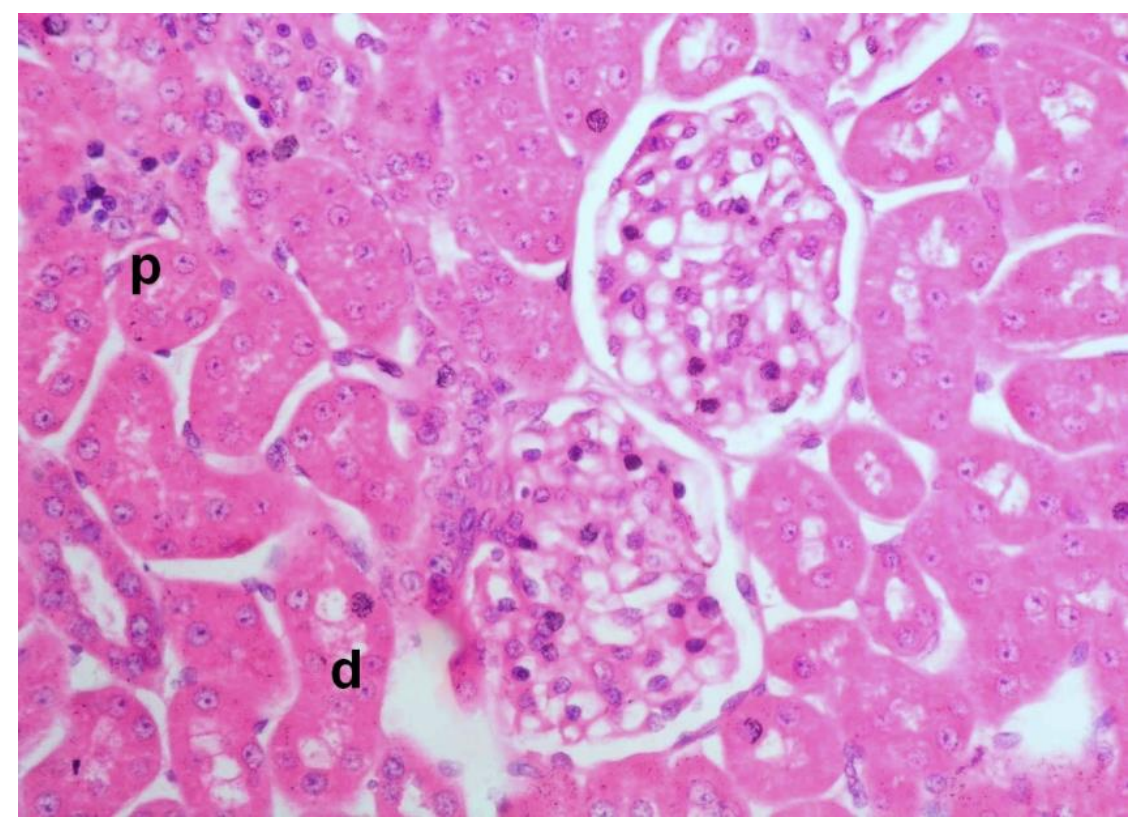

Fig.5: A photomicrograph of section of mini pills treated rabbit kidney cortex showing some distal (d) and proximal (p) tubules with cell swelling and obliterated or narrow lumen.

H\&E X400 


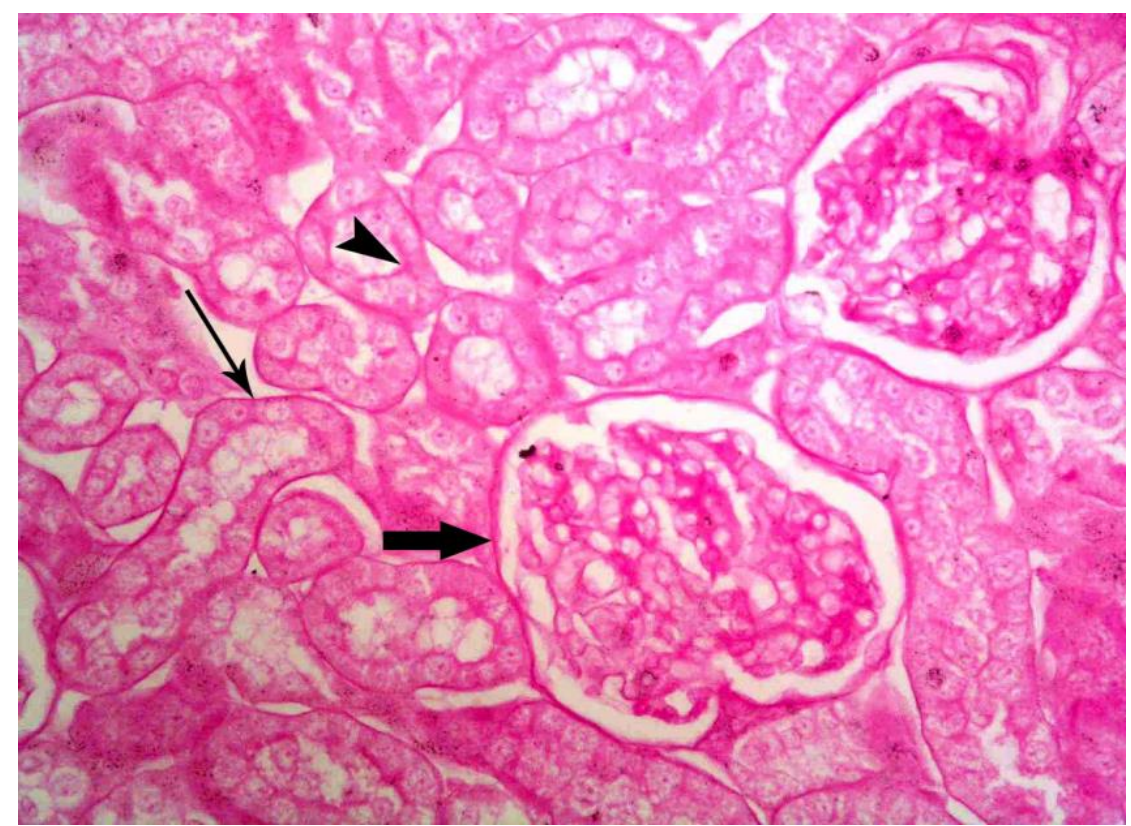

Fig.6: A photomicrograph of section of mini pills treated rabbit kidney cortex showing moderate PAS reaction in capsular (thick arrow) and tubular basement membrane (thin arrow) with mild reaction in brush border of all P.C.T. cells (arrowhead).

PAS reaction $x 400$

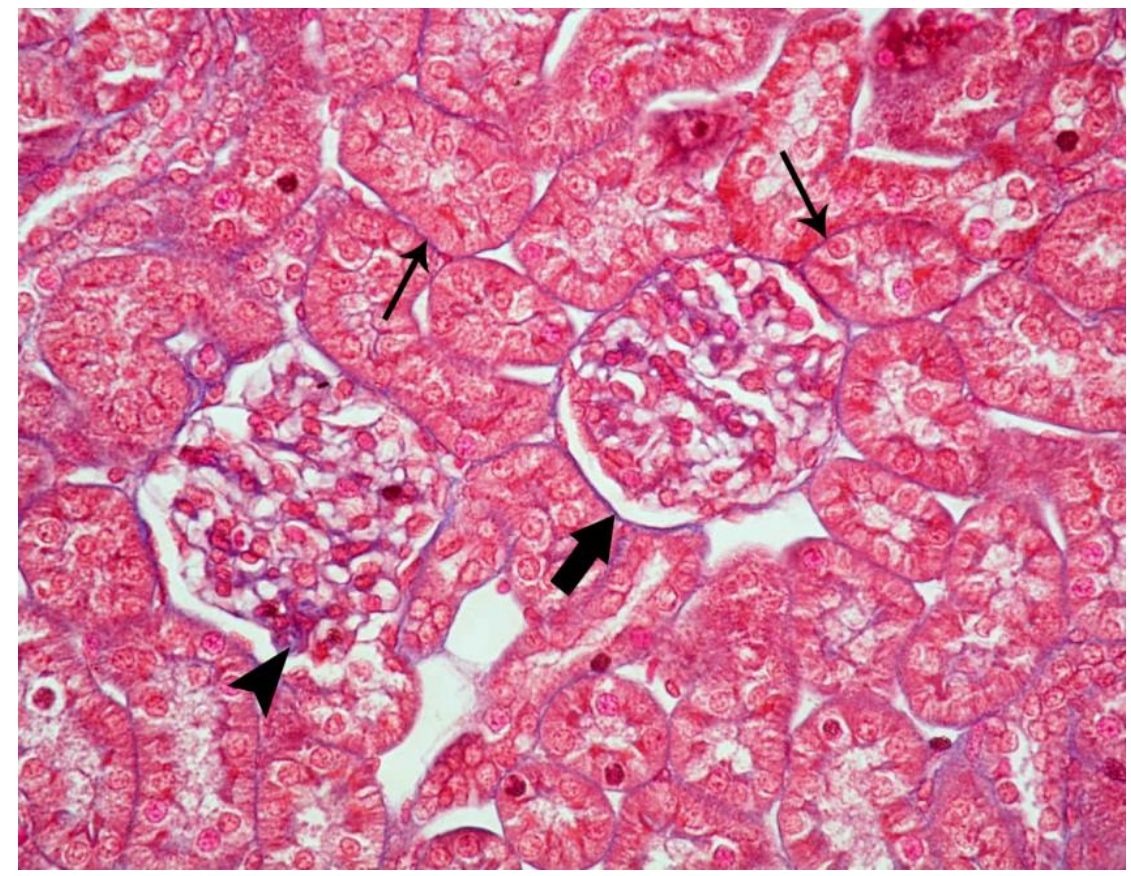

Fig.7: A photomicrograph of section of Mini pills treated rabbit kidney cortex showing moderate increase in collagen content in glomeruli (arrowhead) and around tubular (thin arrow) and capsular (thick arrow) basement membranes.

Masson's trichrome X 400 


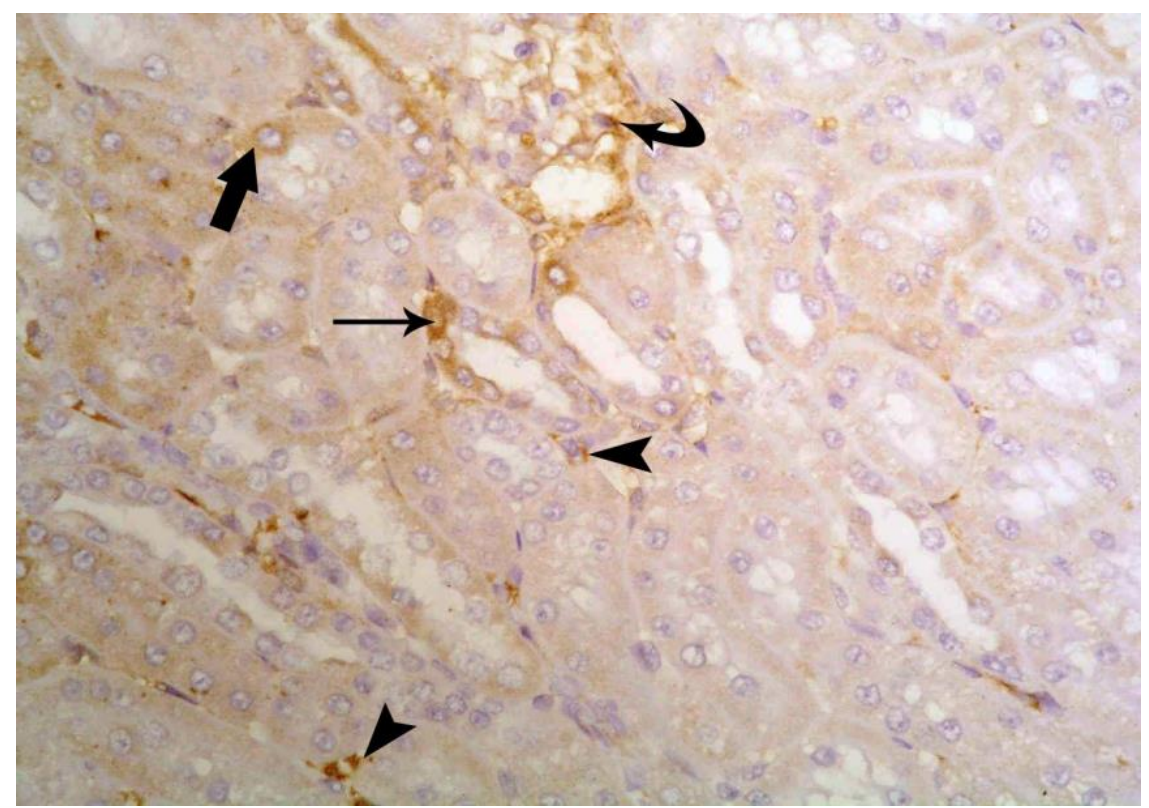

Fig.8: A photomicrograph of section of mini pills treated rabbit kidney cortex showing positive immunoreactivity for angiotensin II in the cytoplasm of some D.C.T. (thin arrow), few P.C.T. (thick arrow) and interstitial cells (arrowhead) and faint in the glomeruli (curved arrow).

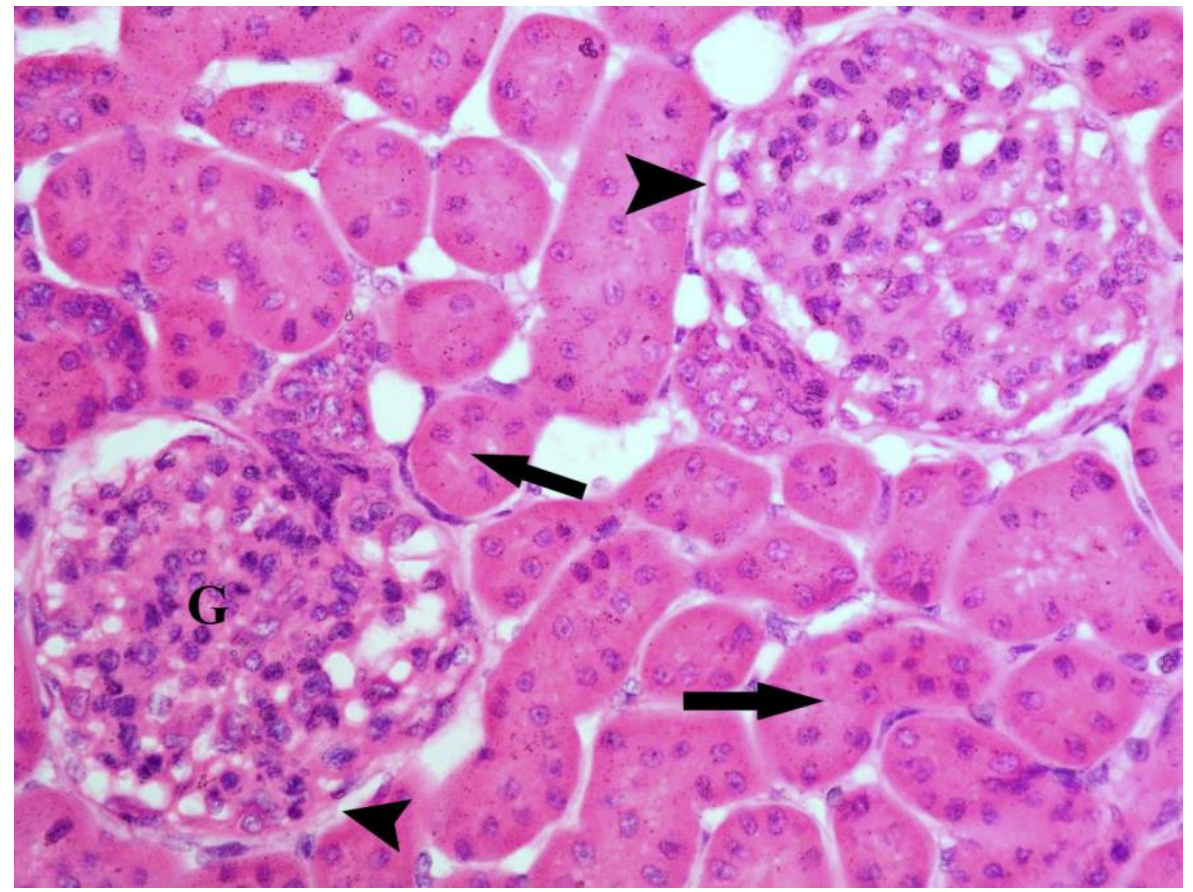

Fig.9: A photomicrograph of section of combined pills treated rabbit kidney cortex showing enlarged renal corpuscles with obliterated Bowman's space (arrowhead), with increased glomerular (G) cellularity. Most of the tubules (arrow) show swollen cells and obliterated tubular lumen.

H\&E X400 


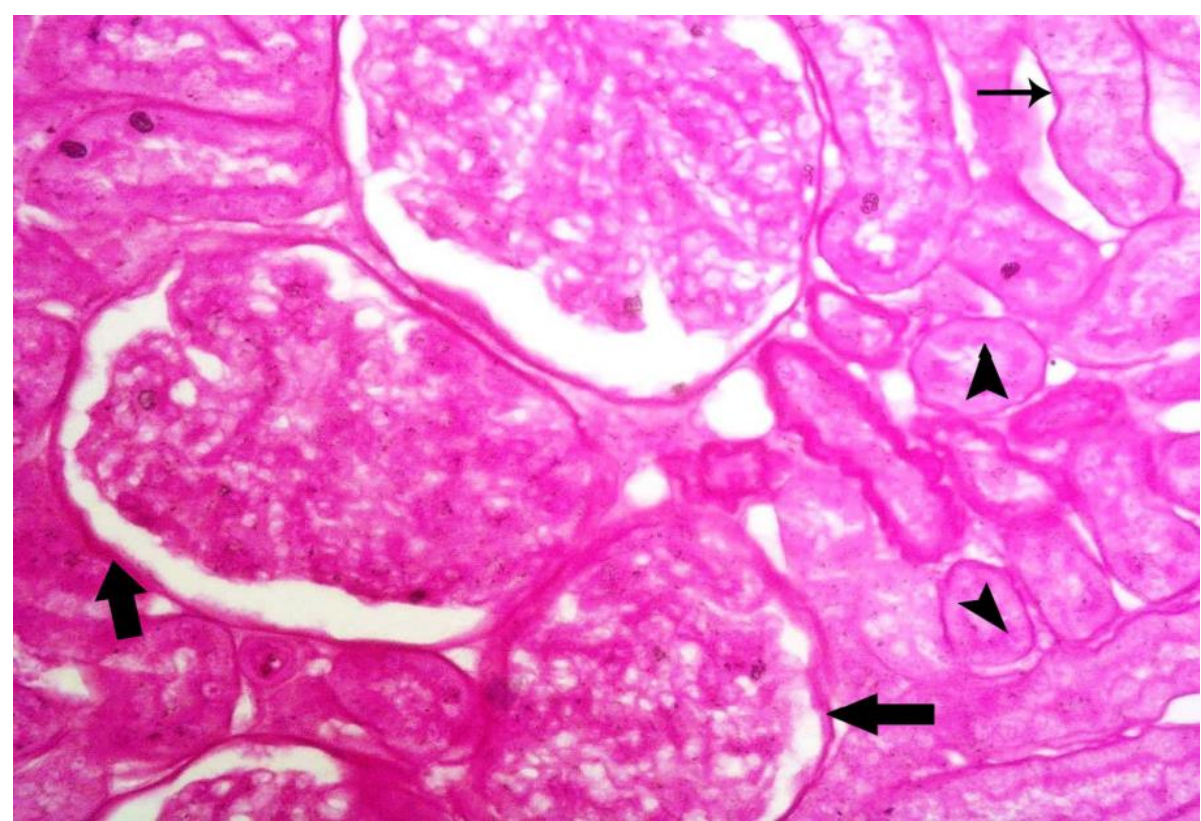

Fig.10: A photomicrograph of section of combined pills treated rabbit kidney cortex showing intensive positive PAS reaction in capsular (thick arrow) and tubular basement membrane (thin arrow). Also a mild PAS reaction of brush border of P.C.T. cells (arrowhead).

PAS reaction $x 400$

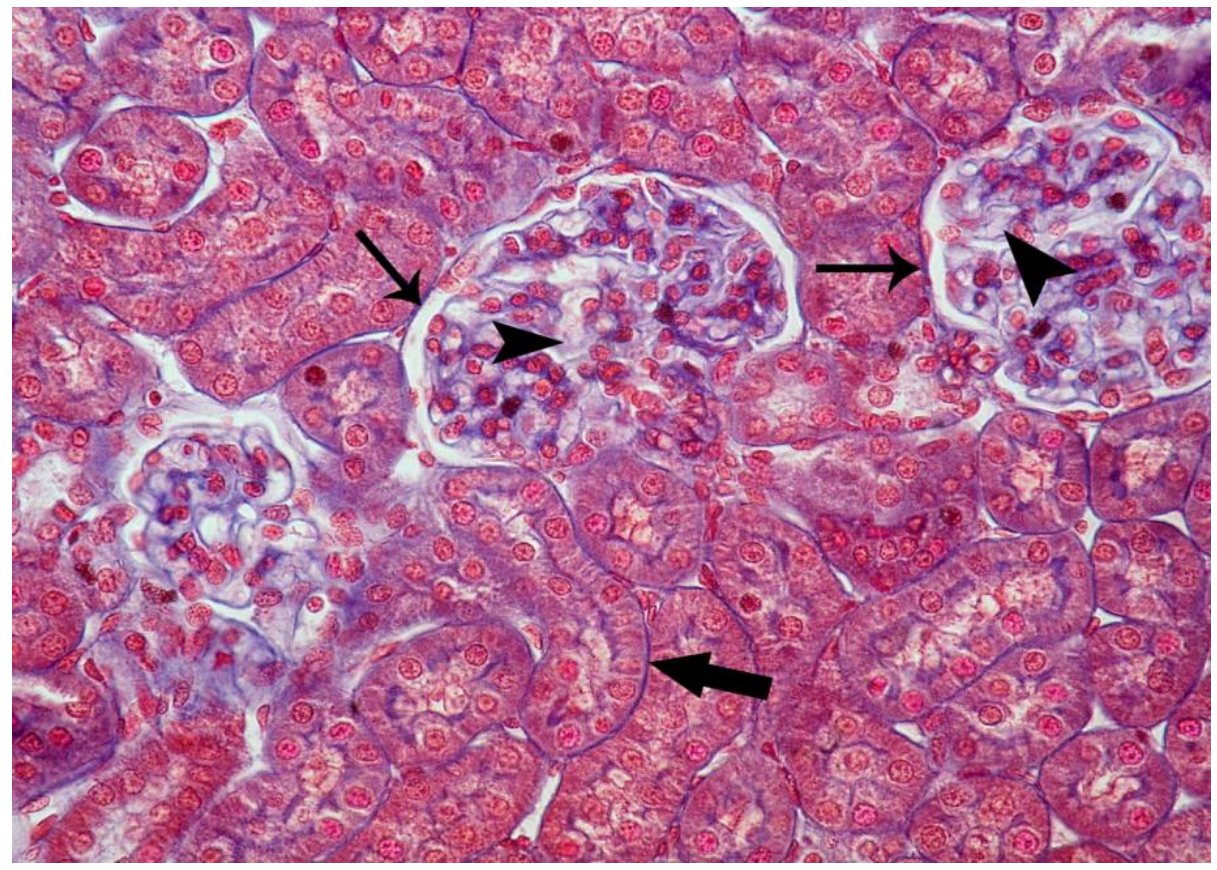

Fig.11: A photomicrograph of section of combined pills treated rabbit kidney cortex showing increased collagenous fiber content in intraglomerular (arrowhead), pericapsular (thin arrow) and peritubular (thick arrow) areas.

Masson's trichrome X 400 


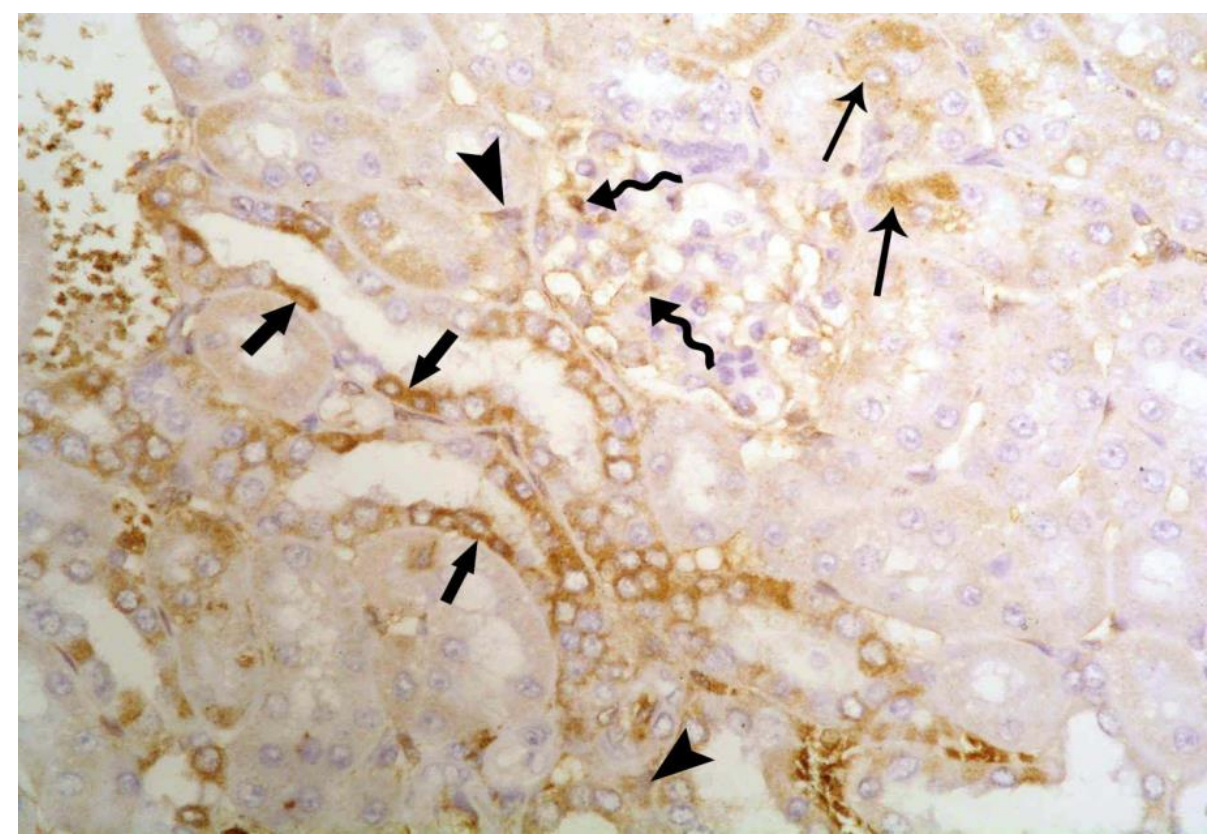

Fig.12: A photomicrograph of section of combined pills treated rabbit kidney cortex showing intensive reaction of immunoreactivity for angiotensin II in the cytoplasm of D.C.T. (thick arrow), P.C.T. (thin arrow) and interstitial cells (arrowhead), but still faint intraglomerular (wavy arrow).

\section{Anti- angiotensin II immunostaining $x 400$}

\section{B- Morphometric results and statistical analysis:}

Measuring the glomerular diameter revealed a statistically significant increase in both mini $(\mathrm{P}=0.0001)$ and combined pills $(\mathrm{P}=0.0001)$ treated groups when compared with the control (Fig.13, table1). There was a non-significant increase in the mean grey of optical density of PAS positive reaction in the mini $(\mathrm{P}=0.703)$ and a significant increase in the combined pills $(\mathrm{P}=0.002)$ treated groups compared with the untreated one (Fig.14, table1). On the other hand, there was a statistically significant increase in the mean area percent of collagen content of mini $(\mathrm{P}=0.0001)$ and combined pills $(\mathrm{P}=0.0001)$ treated groups compared with the control (Fig.15, table1). Moreover, the mean area percent as well as the mean grey of optical density of the anti-angiotensin II positively immunostained cells also showed a statistically significant increase in the mini $(\mathrm{P}=0.006$ and $\mathrm{P}=0.016$ respectively) and combined pills $(\mathrm{P}=0.0001$ and $\mathrm{P}=0.0001$ respectively) treated groups when compared with the untreated one (Figs.16 and 17, table.1). 
Table.1: Mean of all morphometric measurements \pm standard deviation (SD) in all groups.

\begin{tabular}{|c|c|c|c|}
\hline parameters & control & mini pills & combined pills \\
\hline $\begin{array}{l}\text { Mean of glomerular } \\
\text { diameter } \pm \text { SD }\end{array}$ & $74.666 \pm 4.7004$ & $77.52 \pm 3.3614$ & $97.116 \pm 3.6769$ \\
\hline $\begin{array}{l}\text { Mean grey of PAS } \\
\text { optical density } \pm \text { SD }\end{array}$ & $0.268 \pm 0.07436$ & $0.296 \pm 0.07849$ & $0.401 \pm 0.08048$ \\
\hline $\begin{array}{l}\text { Mean area percent of } \\
\text { collagen } \pm \text { SD }\end{array}$ & $11.043 \pm 1.1667$ & $14.725 \pm 0.8072$ & $17.271 \pm 1.6323$ \\
\hline $\begin{array}{l}\text { Mean grey of anti- } \\
\text { AngII immunostaining } \\
\text { 土SD }\end{array}$ & $0.75 \pm 0.1225$ & $0.778 \pm 0.1095$ & $0.888 \pm 0.1643$ \\
\hline $\begin{array}{l}\text { Mean area \% of anti- } \\
\text { AngII immunostaining } \\
\pm \text { SD }\end{array}$ & $12.827 \pm 2.3623$ & $16.021 \pm 1.4265$ & $22.797 \pm 2.3940$ \\
\hline
\end{tabular}

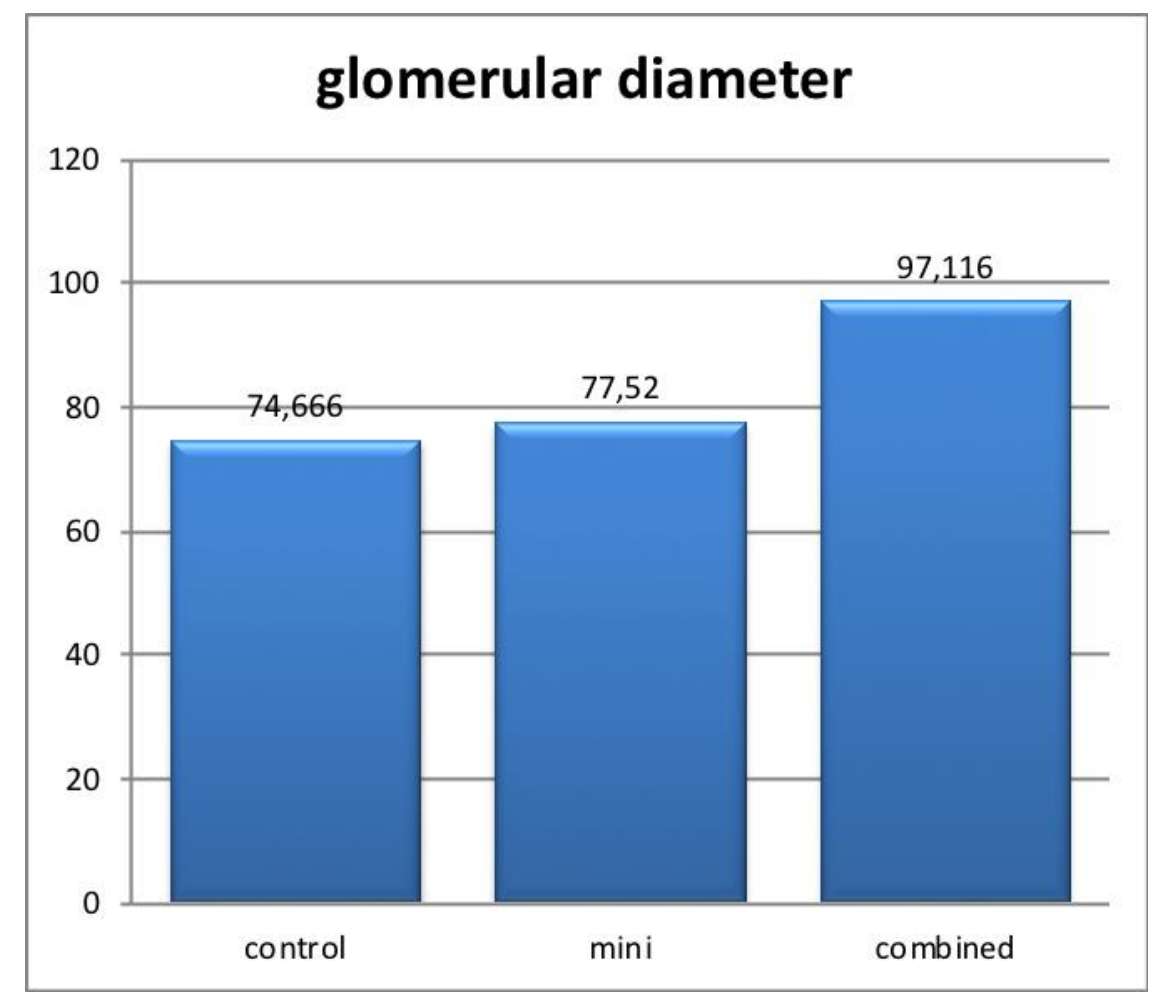


Histological and......

Fig.13: A histogram showing the mean of glomerular diameter in all groups

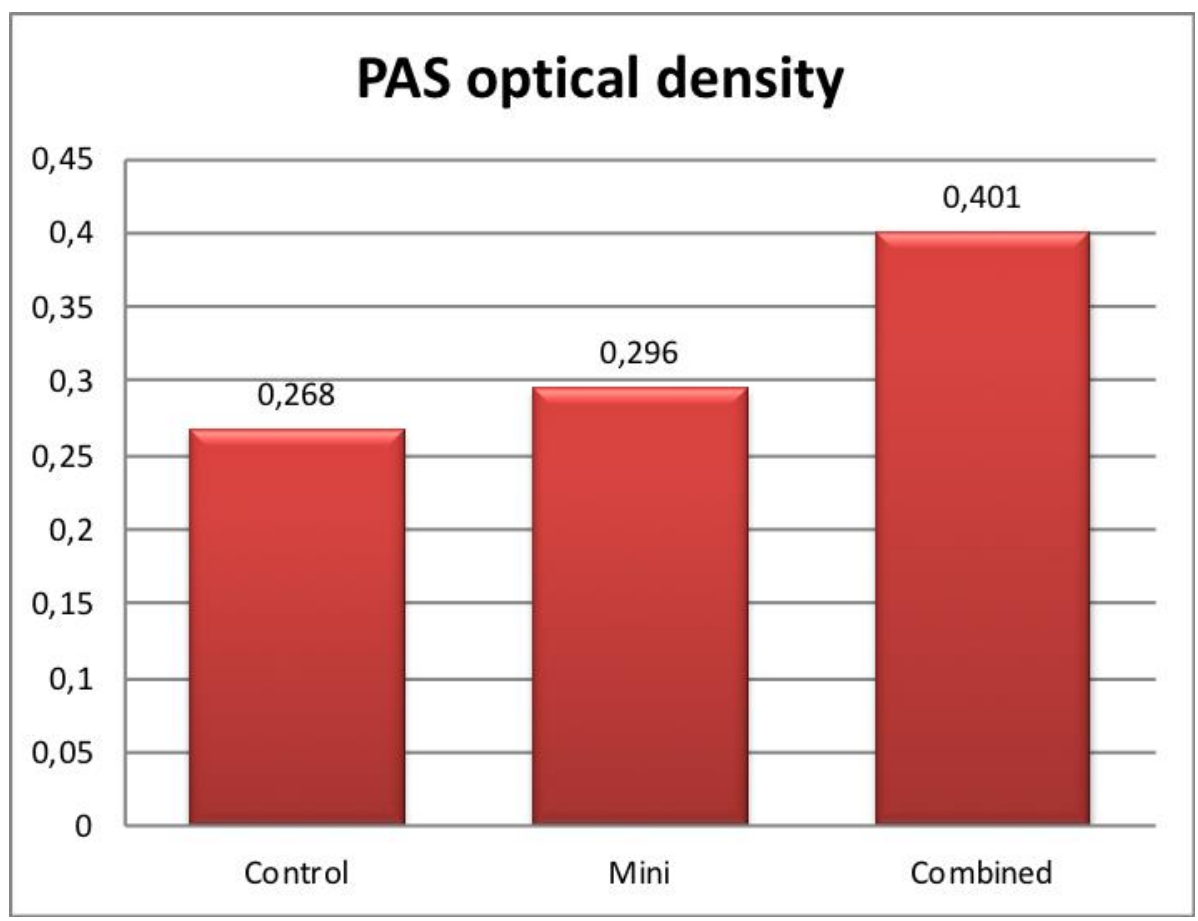

Fig.14: A histogram showing the mean gray of PAS optical density in all groups

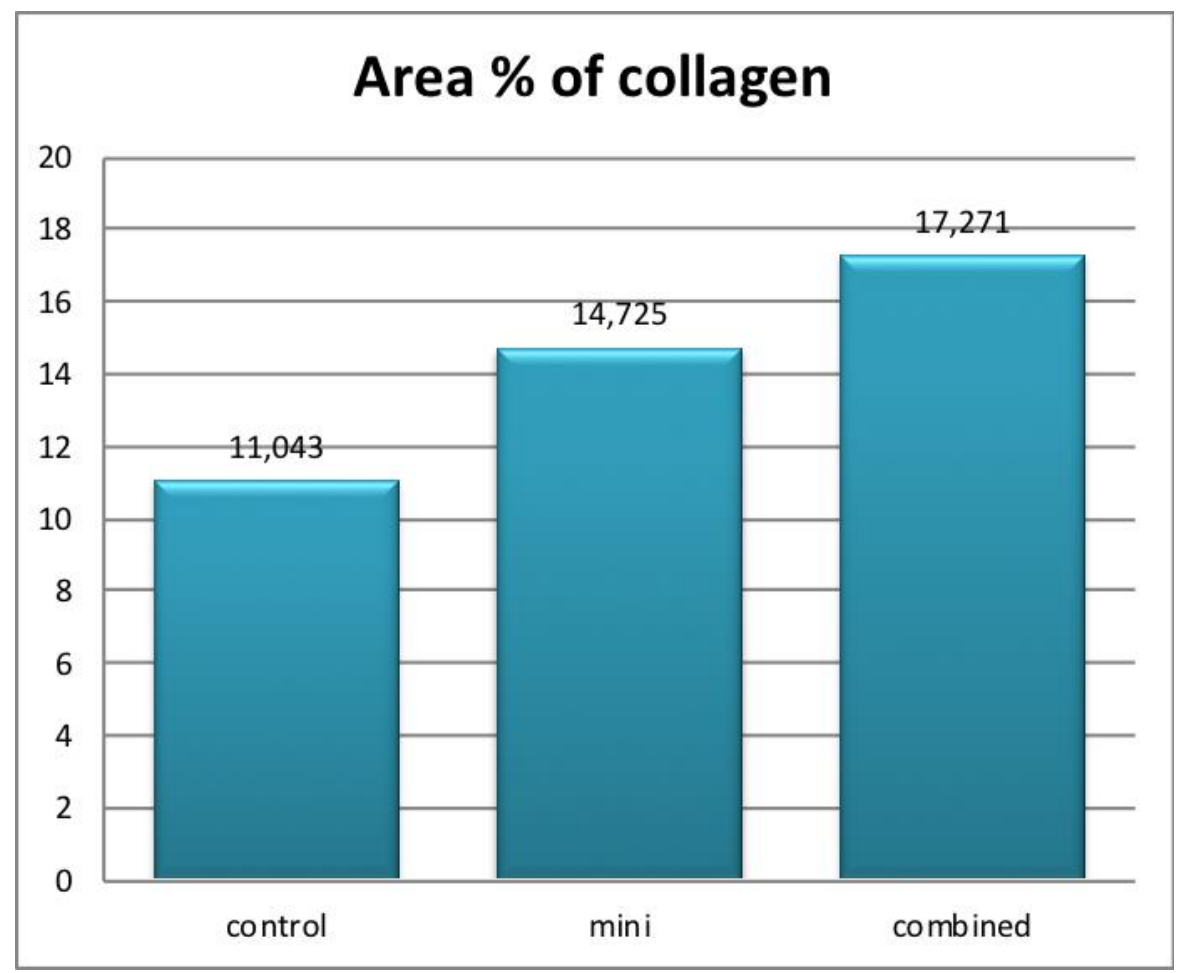

Fig.15: A histogram showing the mean area percent of collagen content in all groups 


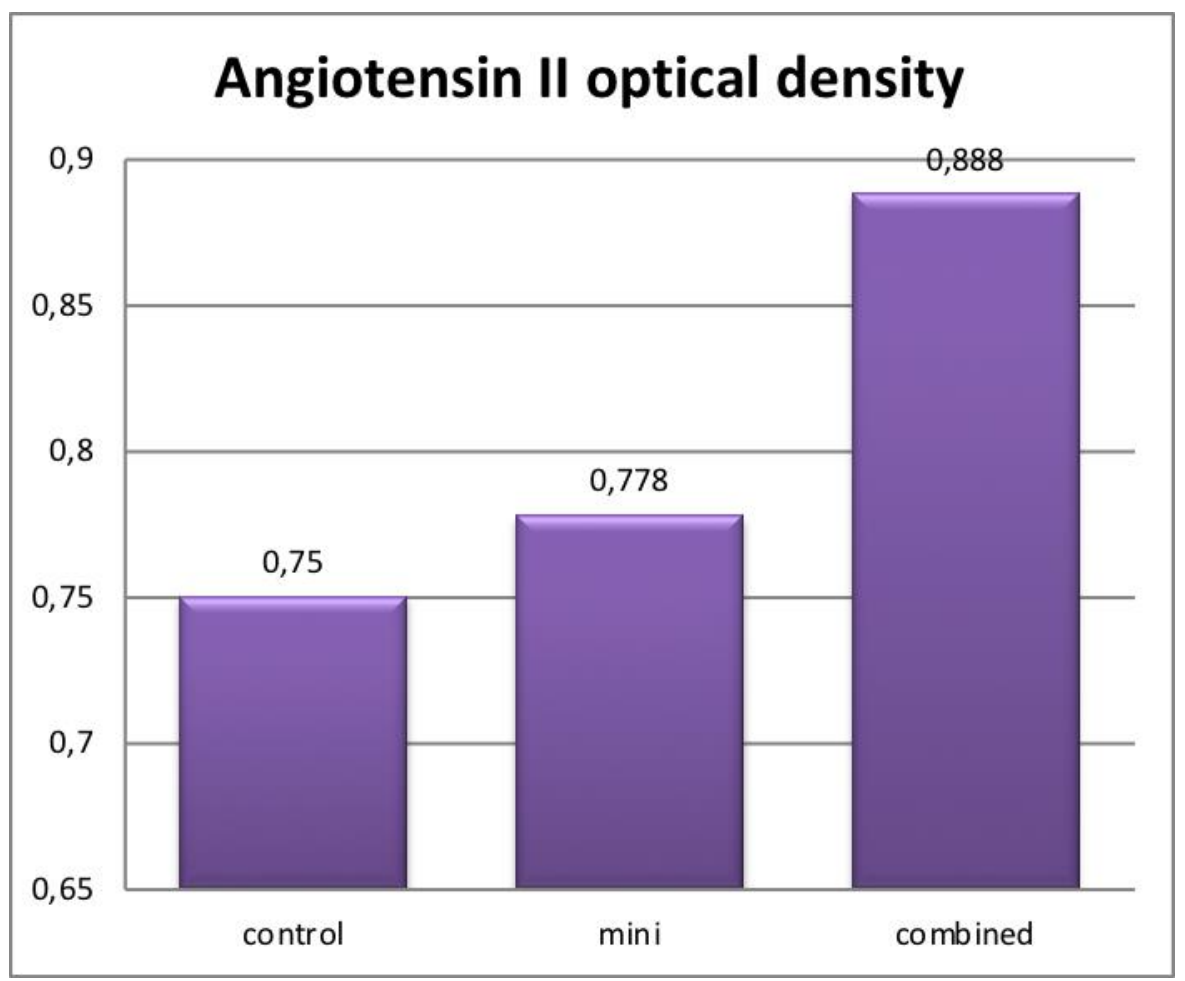

Fig.16: A histogram showing the mean grey of anti-angiotensin II immunoreactivity in all groups

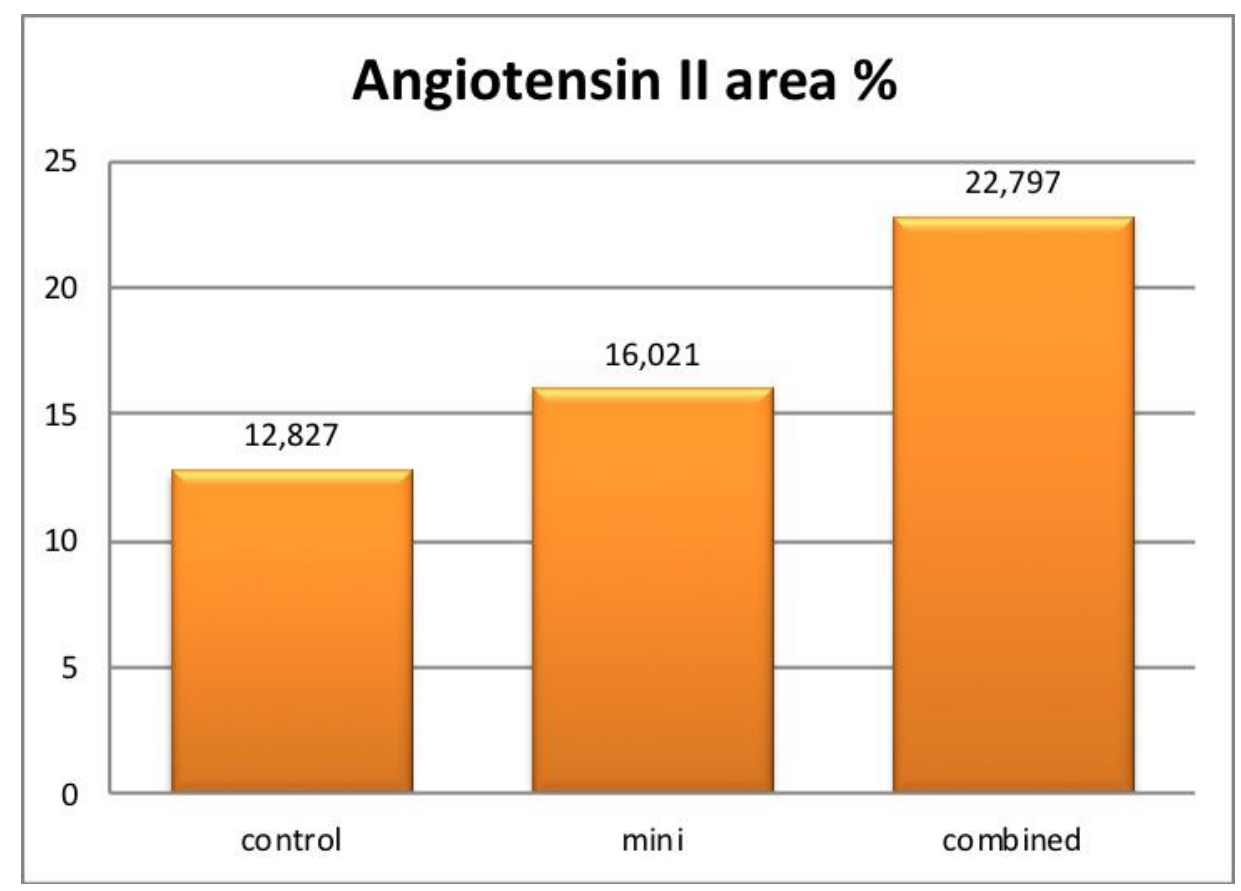

Fig.17: A histogram showing the mean area percent of anti-angiotensin II immunoreactivity in all groups 


\section{Discussion}

The critical role of the circulating reninangiotensin system (RAS) in the regulation of arterial pressure and sodium homeostasis has been recognized for many years. Hussain (2004) stated that up to $5 \%$ of women using combined oral contraceptives (OC) may develop hypertension. Moreover, Olatunji and Soladoye (2008) reported that there is an association between combined $\mathrm{OC}$ and risk of cardiovascular disease.

The present study was designed to detect and compare the changes induced in the kidneys of female rabbits after treatment with mini (progesterone only) or combined (progesterone and estrogen) oral contraceptive pills.

In the current study, mini pills (progesterone only pills) treated rabbits' kidneys showed moderate histological and immunohistochemical alterations. These histological changes were in the form of mild increase in collagen content, as well as a mild to moderate anti-angiotensin II immunopositivity. These results could be supported by Schnare (2002) who stated that progestin-only methods of contraception are much safer than combined pills. Similarly, Hussain (2004) reported that the progestogenonly pill (POP) is a contraceptive option for women who have high blood pressure.

Furthermore, De Leoa et al, (2001) explained that Progesterone has strong natriuretic and antimineralcorticoid activity and brings about a reduction in blood pressure. They added that daily administration of progesterone reduces plasma levels of sodium in humans, causing an increase Ang II and aldosterone.

On the other hand, kidneys of combined pills treated animals, in the present study, showed marked changes like obliterated or narrowed Bowman's space, increased cellularity of glomeruli and tubular cell hypertrophy leading to obliteration of renal tubules lumen. These findings are in agreement with those of Al-Ani et al. (2009) during their study on the effect of OC on the mice kidney. They observed increased cellularity of renal corpuscles and attributed this to mesangial cells proliferation. They suggested that these changes in the renal mesangium of O.C. treated mice might represent hypermetabolic activity due to toxic effect after long-duration of using O.C. Tubular cells hypertrophy could be explained by the reports of Wolf and Nelson (1990) and Morgan et al. (1996) who reported that angiotensinogen increase in proportion to estrogen therapy that leads to an excessive Ang II production. Moreover, Kobori, et al. (2007) found that Ang II participates in a variety of renal tubular alterations, including induction of cellular hypertrophy and oxidative stress. They added that the angiotensin1 receptors are suggested to contribute to the tubular cell hypertrophy.

In the present study, the PAS reaction revealed thickening of the capsular and tubular basement membranes that was more marked in combined pills treated animals. This is in coordination with Al-Ani et al (2009) who observed glomerular basement membrane thickening with excessive amount of electron dense deposits in OC treated mice. They proposed that this is a result of mesangial cells proliferation leading to obliteration of capillary lumen and glomerusclerosis.

Also, in the present work, after treatment with combined pills, an intensive collagenous content was noticed around renal tubules and corpuscles. This could be attributed to the increase in intrarenal AngII. This assumption could be supported by the work of Kagami et al. (1994) who reported that the disturbance in reninangiotensin system and in active angiotensin peptides, angiotensin II, may be an important mechanism in the development of interstitial fibrosis and glomerulosclerosis. In the same context, Wolf et al. (1992) found that Angiotensin II stimulated the proliferation and biosynthesis of type I collagen in cultured murine mesangial cells. Furthermore, Yamamoto et al (2007) also stated that the increase in intrarenal AngII activity was also shown to parallel the severity of fibrotic renal damage.

This is further substantiated by the intense immune reaction of anti-angiotensin II that was detected in renal tubules and interstitial cells, after combined pills treatment in the present work. This could be supported by the report of 
Goldhaber et al. (1984) who stated that estrogen treatment stimulates the hepatic production of the renin substrate angiotensinogen which in turn leads to an increase of Ang II. Moreover, Morgan et al (1996) stated that plasma angiotensinogen concentrations increase two to three folds in response to estrogens in premenopausal women using oral contraceptives. This is also in accordance with Kang et al. (2001) who demonstrated significantly higher plasma concentrations of angiotensinogen, Ang II and aldosterone in OCs female human users. On the other hand, this is in partial agreement with Baillargeon et al. (2005) who stated that estrogen stimulated the hepatic production of the renin substrate angiotensinogen and they found that the usage of combined OCs resulted in a dramatic increase in angiotensinogen but only marginally increased Ang II. Thus, it could be deduced that the changes in AngII immunoreactivity, which were observed in the present study, could be attributed to the estrogen component in the combined OC pills.

Accordingly, it could be concluded that the mini (progesterone only) pills had less marked histological effects on the kidney as compared to the combined (estrogen and progesterone) pills in female rabbits. Therefore, the POPs are to be recommended as a safer contraceptive measure, specially in women suffering from mild renal impairment or elevated blood pressure. It is also recommended to regularly check the blood pressure and the kidney functions of combined oral contraceptive users, if any elevation of blood pressure or signs of renal impairment should appear the use of another method of contraception is advisable.

\section{References}

Abadir M (2011):The Frail Renin-Angiotensin System. J Geriatric Med.; 27(1): 53-65

Al-Ani IM, Noor Al-Deen JA and Kashmola MA (2009): Light and Transmission Electron Microscopic Study on the Effect of Contraceptive Pills on the Glomerulus and Juxtaglomerular Apparatus in Mice. Ann Micros.; 9:63-72

Baillargeon JP, McClish DK, Essah PA and Nestler JE (2005): Association between the current use of low-dose oral contraceptives and cardiovascular arterial disease: a meta-analysis. J Clin Endocrinol Metab.; 90:3863-3870

Bancroft J and Gamble M (2002): Theory and Practice of Histological Techniques, $5^{\text {th }}$ edn., Churchil Livingston, London: 231.

Carol A (2005): History of contraception. J Women's Health Med.; 2:5-9

Darrell $H$ and Melissa L (2008): Drug-Induced Hypertension: Estrogens and Progestins. J US Pharmacist; 33 (9): HS11-HS20

David F, Archer G, Susan A, Ballagh G and Grubb S (2009): Ovarian activity and safety of a novel levonorgestrel/ethinyl estradiol continuous oral contraceptive regimen. J Contraception; 80(3): 245253

De Leoa V, la Marcaa A, Morgantea G, Lucanib B, Namib R, Ciottac L, Ciancic A and Petragliaa F (2001): Evaluation of plasma levels of reninaldosterone and blood pressure in women over 35 years treated with new oral contraceptives. J Contracept.; 64: 145-148

Goldhaber SZ, Hennekens CH, Spark RF, et al. (1984): Plasma renin substrate, renin activity, and aldosterone levels in a sample of oral contraceptive users from a community survey. J Am Heart; 107: 119-122

Hussain S F (2004): Progestogen-only pills and high blood pressure: is there an association?: A literature review. J Contracept; 69 (2): 89-97

Kagami W, Border D, Miller $\mathbf{E}$ and Noble $\mathbf{N}$ (1994): Angiotensin II stimulates extracellular matrix protein synthesis through induction of transforming growth factor $\beta$ expression in rat glomerular mesangial cells. J Clin Invest, 93: 2431-2437.

Kang AK, Duncan JA, Cattran DC, Floras JC, Lai V, Scholey JW and Miller JA (2001): Effect of oral contraceptives on the renin angiotensin system and renal function. Am J Physiol Regul Integr Comp Physiol; 280: R807-R813.

Kobori H, Nangaku M, Navar G and Nishiyama A (2007): The Intrarenal Renin-Angiotensin System: From Physiology to the Pathobiology of Hypertension and Kidney Disease. J Pharmacol Rev; 59(3): 251-287

Leung S and Chappell C (2003): A local pancreatic renin-angiotensin system: endocrine and exocrine roles. Int Biochem Cell Biol; 35: 838-846

Morgan L, Broughton F, Pipkan G and Kalsheker N (1996): Angiotensinogen: molecular biology, biochemistry and physiology. Int J Biochem Cell Biol; 28(11):1211-1222

Olatunji L and Soladoye A (2008): Oral contraceptive administration aggravates nitric oxide synthesis inhibition-induced high blood pressure in female rats. J Pathophysiol; 15: 221-226 
Paget GE and Barnes JM (1964): Evaluation of Drug Activities, $2^{\text {nd }}$ edn., Laurence D.R. and Bacharach A.L. (eds), Academic press, New York, USA: 135

Petrie A and Sabin C (2005): Medical Statistics at a Glance, $2^{\text {nd }}$ edn., Sugden M and Moore K eds., Blackwell Publishing LTD., USA:55

Reed S (2009): Essential Physiological Biochemistry: An organ-based approach. $1^{\text {st }}$ edn.; John Wiley \& Sons Ltd., UK: 84.

Schnare M S (2002): Progestin Contraceptives. J Midwif Women's Health; 47(3): 157-66.
William J. and Stephen K (2007): Clinical Chemistry Book, $6^{\text {th }}$ edn; London: 216.

Wolf $G$ and Nelson FG (1990): Angiotensin ii induces cellular hypertrophy in cultured murine proximal tubule cell. Am J Physiol; 259: F.768-F.777 Yamamoto T, Nakagawa T, Suzuki H, Ohashi N, Fukasawa H, Fujigaki Y, Kato A, Nakamura Y, Suzuki F and Hishida $\mathbf{A}($ 2007): Urinary Angiotensinogen as a Marker of Intrarenal Angiotensin II Activity Associated with Deterioration of Renal Function in Patients with Chronic Kidney Disease J Am Soc Nephrol 18: 1558-1565. 


\title{
دراسة هستولوجية وهستوكيميائية مناعية علي التغيرات المحدثة بفعل حبوب منع الحمل فى كلى انثى الارنب التفرات
}

\author{
دينا حلمي عبد القادر * محمد سيد جبرى ** , منى عبد الرحمن ابراهيم ** بسمة نصر حسن **

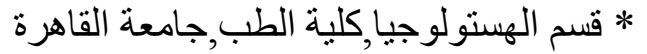

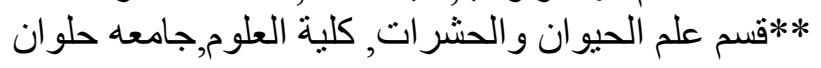

تظل آلية حدوث ضغط الدم بعد استخدام حبوب منع الحمل غير واضحة. الدلائل التجريبية تؤكد

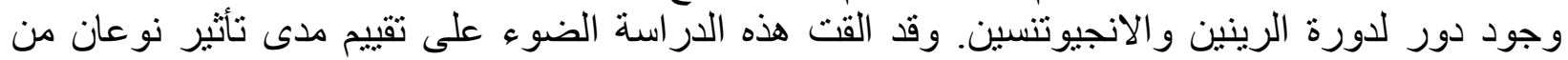

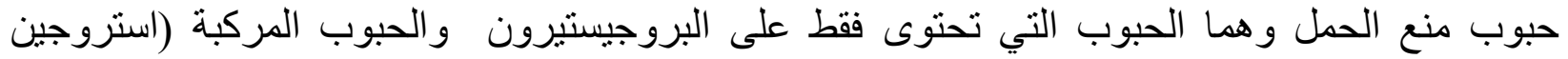

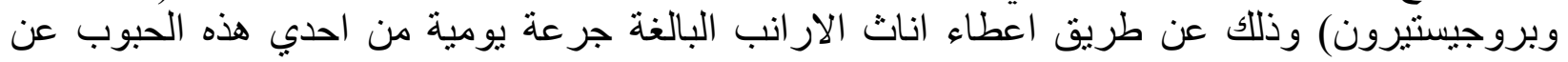

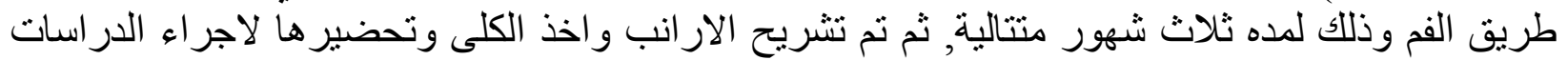

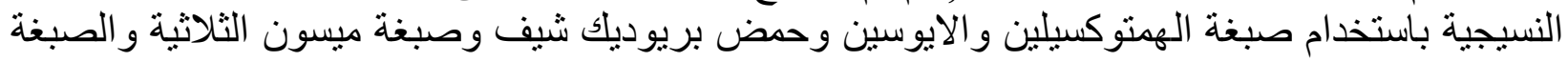

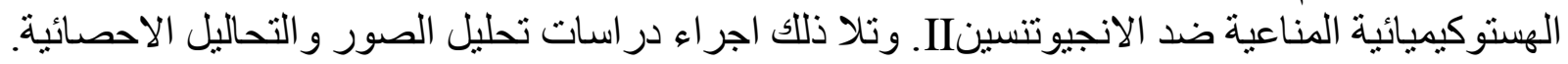

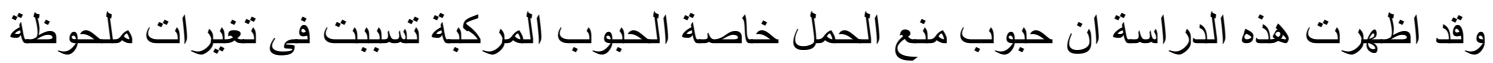

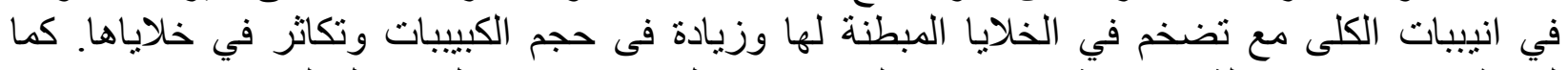

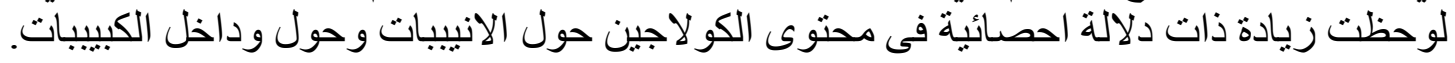

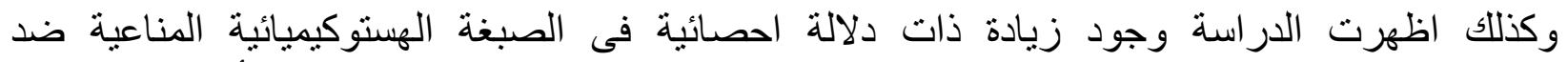

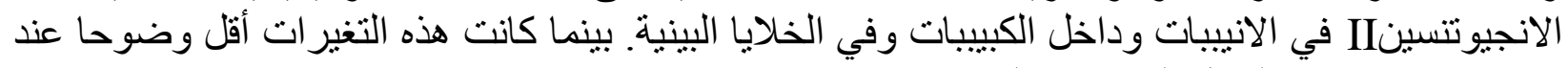

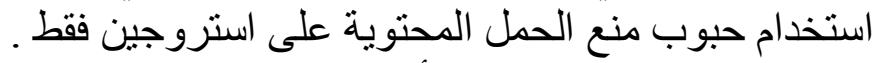

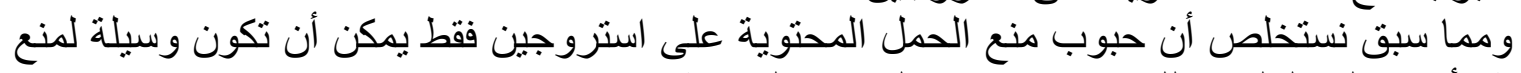
الحمل أكثر أمانا علي الكلي وذللك عند مقارنتها بالحبوب الحبل المركبة. 